\title{
Лапароскопическая холецистәктомия при остром калькулезном холецистите у больных, ранее оперированных на органах брюшной полости
}

н. В. Черкова

Харьковский национальный университет имени В. Н. Каразина

\section{Laparoscopic cholecystectomy in an acute calculous cholecystitis in patients, who earlier were operated on abdominal organs}

\author{
N. V. Cherkova \\ V. N. Karazin Kharkov National University
}

Реферат

Цель. Изучение эффективности дооперационной диагностики и лапароскопических методов коррекции спаечной болезни (СБ) у больных с острым калькулезным холециститом (ОКХ).

Материалы и методы. Проведен анализ эффективности дооперационной диагностики и лапароскопических методов коррекции СБ у 110 пациентов с ОКХ, ранее перенесших оперативные вмешательства на органах брюшной полости.

Результаты. Диагностическая ценность сонографии при СБ высокая. Использование ультразвукового скальпеля (УЗС) у больных с выраженными местными воспалительными изменениями тканей в области желчного пузыря и сопутствующей СБ имеет преимущества.

Выводы. Применение УЗС - наиболее эффективный и безопасный метод рассечения спаек и разъединения инфильтрата при ОКХ.

ключевые слова: рассечение спаек; острый калькулезный холецистит; лапароскопическая холецистәктомия; ультразвуковой скальпель.

\section{Abstract}

Objective. Studying of efficacy of preoperative diagnosis and laparoscopic methods of treatment for the adhesive disease (AD) in patients, suffering an acute calculous cholecystitis (ACCH).

Materials and methods. Analysis of efficacy of preoperative diagnosis and laparoscopic correction methods for AD in 110 patients, suffering ACCH, operated earlier on abdominal organs.

Results. Diagnostic validity of ultrasonography in AD is high. Application of ultrasonic scalpel (USS) in patients, suffering pronounced local inflammatory changes in tissues of the gallbladder region and concurrent $\mathrm{AD}$, has advantages.

Conclusion. Application of USS constitute the most effective and secure method of the adhesions and infiltrate dissection in $\mathrm{ACCH}$.

Keywords: dissection of adhesions; acute calculous cholecystitis; laparoscopic cholecystectomy; ultrasonic scalpel.

Наличие спаечного процесса в брюшной полости существенно увеличивает опасность ятрогенных повреждений органов брюшной полости при создании пневмоперитонеума и введении троакаров, ограничивает доступ к операционному полю и его обзор [1-3]. При СБ используется открытый метод введения первого троакара (метод Хассана) [1, 2, 4].

Рассечение спаек - один из наиболее частых этапов симультанных лапароскопических операций при лапароскопической холецистэктомии (ЛХЭ). Симультанные операции (СО) в билиарной хирургии выполняют наиболее часто, что связано с высокой частотой желчнокаменной болезни (ЖКБ). При ЖКБ СО выполняют у $2,9-22,1 \%$ больных $[1,3,5]$. Несмотря на разработку показаний и противопоказаний к СО, методов и объемов хирургических вмешательств, хорошие результаты, достижения в хирургии, практические хирурги довольно сдержанно относятся к их выполнению при ОКХ.
При ЖКБ частота СО у больных с ОКХ, ранее оперированных на органах брюшной полости, составляет 6,9 30\%. Послеоперационные осложнения возникают у 0,2 - 23,9\% пациентов, летальный исход регистрируют у 2 $-20 \%[1,2]$.

Число пациентов с ОКХ, ранее оперированных на органах брюшной полости, имеет тенденцию к увеличению $[2,3,6]$.

До настоящего времени наиболее спорными вопросами в лечении ОКХ остаются сроки выполнения хирургического вмешательства и определение вида операции, особенно у больных, ранее перенесших оперативные вмешательства на органах брюшной полости.

Цель исследования: изучить эффективность дооперационной диагностики и лапароскопических методов коррекции СБ у больных с ОКХ, оценить эффективность новых хирургических технологий при ЛХЭ и рассечении спаек. 


\section{Материалы и методы исследования}

В клинике хирургических болезней на базе Харьковской клинической больницы на железнодорожном транспорте №2 за период с 2007 по 2017 г. ЛХЭ выполнена у 110 пациентов с ОКХ, ранее оперированных на органах брюшной полости. Больные разделены на 2 группы в зависимости от способа выделения и обработки ложа желчного пузыря и выполнения рассечения спаек.

В 1-ю группу вошел 61 пациент, у которого выделение желчного пузыря, обработку его ложа и рассечение спаек производили с использованием монополярной электрокоагуляции.

Во 2-й группе было 49 пациентов, у которых выделение желчного пузыря, обработку его ложа и рассечение спаек выполняли при помощи УЗС Harmonic Ultracision (Ethicon, США). Все больные дали информированное добровольное согласие на медицинское вмешательство. Возраст больных - от 19 до 76 лет. Женщин было 87, мужчин - 23. Из 110 пациентов дважды оперированы 12, трижды - 11. Давность заболевания варьировала от 5 ч до 5 и более сут. Лишь 15,9\% больных были госпитализированы в сроки до 6 ч от начала заболевания. У $32,2 \%$ пациентов давность заболевания составила 6 24 ч, а 51,9\% больных поступили в хирургическое отделение позже 24 ч с момента развития ОКХ.

Вероятность выполнения ЛХЭ при ОКХ у больных, ранее перенесших оперативные вмешательства на органах брюшной полости, является одной из наиболее актуальных проблем современной абдоминальной хирургии, поэтому необходима точная диагностика висцеропариетальных спаек и совершенствование способов оперативных вмешательств при данной патологии. Определяя вероятность наличия спаек в брюшной полости, учитывали данные анамнеза, клиническую картину, характер и локализацию послеоперационных рубцов, результаты ультразвукового исследования (УЗИ).

\section{Результаты}

Достоверной и информативной в диагностике СБ является сонография. Независимо от локализации в брюшной полости, спайки имели практически одинаковую эхографическую картину, характер которой определяла степень выраженности рубцовых изменений. При ультразвуковой визуализации у 40 (47,1\%) больных спайки лоцировались как эхопозитивные включения вытянутой формы или в виде мелкоточечных образований. На әхограммах у 10 (11,8\%) больных множественные спайки сливались, формируя небольшие глыбчатые конгломераты неправильной, овальной или округлой конфигурации. У 5 (5,9\%) больных спаечный процесс был представлен в виде эхопозитивного неоднородного тяжа. Сочетание рубцовых изменений различной формы выявлено у 10 (11,8\%) больных. При СБ отмечали отсутствие или ограничение подвижности париетального и висцерального листков брюшины. У 30 (35,3\%) больных наблюдали симптом «пружины» - обратное возвращение вовлеченной в спаечный процесс зоны за счет эластических свойств спаек, у 15 (17,6\%) - симптом «кулисы» - лоцировалась линейная эхопозитивная структура, деформирующая петлю кишечника и нарушающая пассаж по кишечнику.
На основании дооперационного обследования у 97 (88,2\%) больных спаечный процесс был диагностирован до ЛХЭ, у 13 (11,8\%) он явился операционной находкой. Это свидетельствует о высокой диагностической ценности УЗИ при распознавании СБ. Одной из причин повреждения полых органов на этапе холецистэктомии чаще всего бывает выраженный спаечный процесс, несоблюдение правил коагуляции и визуального контроля в ходе введения инструментов в зону операции. Наибольшую опасность представляют так называемые просмотренные повреждения.

\section{Обсуждение}

Методика ЛХЭ была стандартной. Первый троакар вводили только открытым методом (по Хассану). Затем выполняли лапароскопическую ревизию брюшной полости, результаты которой определяли дальнейший ход операции. Последующие троакары устанавливали под контролем лапароскопа в точках, свободных от спаечного процесса и адекватных для выполнения последующего оперативного вмешательства. Если обширные сращения не позволяли ввести хотя бы один троакар в намеченных точках, вводили троакар в свободной от сращений точке и освобождали переднюю брюшную стенку от спаек в местах предстоящего введения остальных троакаров. Первичное рассечение спаек выполняли для введения троакаров под зрительным контролем и достаточного доступа к желчному пузырю, необходимого для безопасного и удобного его удаления. После выполнения холецистэктомии до извлечения желчного пузыря из брюшной полости выполняли окончательное рассечение спаек.

Для рассечения тканей использовали электрокоагуляцию (1-я группа больных) и УЗС (2-я группа). Рассечение спаек выполняли последовательно, начиная с подвижных тяжей, пленчатых спаек и сращений сальника с другими органами и тканями. Перед рассечением винтообразно дислоцированных в сагиттальной плоскости сращений полых органов с париетальной брюшиной, окутанных большим сальником, необходимо провести осмотр данной зоны хотя бы из двух диаметрально противоположных точек.

Таким образом удается выбрать наиболее безопасное место для начала рассечения спаек, определить оптимальные позиции для установки остальных инструментов.

Наиболее эффективным и безопасным методом разъединения сращений являлось использование УЗС, которое позволяло без клипирования пересекать сосуды до 3 мм в диаметре с надежным гемостазом. Кроме того, после разъединения сальниковых сращений с помощью УЗС не было повышенной кровоточивости и микрогематом тканей, что нередко наблюдали при рассечении спаек с использованием электрокоагуляции. У больных с ОКХ, особенно при развитии перивезикального инфильтрата в области шейки желчного пузыря, нарушаются топографоанатомические отношения элементов печеночно-двенадцатиперстной связки и треугольника Кало, что может вызвать их повреждение, в первую очередь общего желчного протока. Кроме того, разделение отечных и воспаленных тканей сопровождается интен- 
сивным кровотечением, что также затрудняет проведение эндовидеохирургических операций.

Во 2-й группе больных, оперированных с применением УЗС, отмечена высокая интенсивность ультразвукового воздействия на мягкие ткани, так как разъединение их не представляло труда, что позволяло четко определить слои тканей. Разрушающий эффект на кровеносные сосуды и желчные протоки был значительно меныше. Процесс выделения желчного пузыря происходил эффективнее без повреждений сосудов, протока и стенки пузыря. Контактную обработку этих образований с использованием тупой части инструмента производили для подготовки к клипированию. Рассечение тканей было быстрым, коагуляция обеспечивала стойкий гемостаз. При коагуляции и диссекции ткани не прилипали к рабочей части УЗС, что исключало возможность термического или механического повреждения окружающих органов. Кроме того, рассечение и коагуляция тканей сопровождались меньшим выделением тепла и меньшим нагреванием оперируемых органов, при этом они мало отличались от интактных тканей по структуре и форме. О наступивших в них изменениях свидетельствовали некоторое изменение их цвета и снижение блеска брюшины. Также отсутствовала карбонизация тканей, которая значительно выражена после электрохирургической диссекции. Бескровное операционное поле обеспечивало лучший визуальный контроль места диссекции ткани. Применение УЗС позволило коагулировать кровеносные сосуды до 3 мм в диаметре, тогда как электрокоагуляционный гемостаз был эффективен для сосудов до 2 мм в диаметре с последующим их клипированием.

Полученные результаты позволяют судить о преимуществах использования УЗС, особенно при технически сложных этапах мобилизации желчного пузыря у больных с выраженными местными воспалительными изменениями тканей, в частности при деструктивных формах ОКХ. Применение УЗС позволило сократить продолжительность вмешательства, снизить операционную травму, обеспечить надежный гемостаз, а также добиться быстрой реабилитации пациентов.

\section{Выводы}

1.Спаечный процесс в брюшной полости не является противопоказанием к выполнению лапароскопических операций, поэтому для определения локализации висцеропариетальных сращений у ранее оперированных пациентов на дооперационном этапе необходимо выполнять УЗИ.

2. Использование УЗС у пациентов с ОКХ, ранее оперированных на органах брюшной полости, а также при осложненных формах данного заболевания сопровождалось незначительным нагреванием тканей в области контакта, отсутствием обугливания тканей, минимальным краевым повреждением, меньшим разрушительным эффектом на эластичные трубчатые структуры, к которым относятся сосуды и желчные протоки, что позволило выделять их не травмируя, тем самым создавая благоприятные условия для оптимального заживления раны.

\section{References}

1. Vasyliuk MD, Shevchuk AH, Kozan YaI. Laparoskopichna ta tradytsiina kholetsystektomiia i symultanni operatsii na orhanakh cherevnoi porozhnyny. Suchasni medychni tekhnolohii. 2011;4(3):52-5. [In Ukrainian].

2. Odishelashvili GD, Ismailov JeH. Vybor sposobov ostanovki krovotechenija pri povrezhdenii pecheni. Astrahanskij medicinskij zhurnal. 2012;1(7):124-6. [In Russian].

3. Lezana Perez MA, Carreno Villarreal G, Lora Cumplido P, Alvarez Obregon R. Comparative study of ambulatory laparoscopic cholecystectomy versus management of laparoscopic cholecystectomy with conventional hospital stay. 2013;7(91):424-1.

4. Puchkov KV, Puchkov DK. Rezul'taty primenenija miniinvazivnyh laparoskopicheskih metodik $\mathrm{v}$ lechenii zabolevanij zhelchnogo puzyrja. Al'manah Instituta hirurgii im. A. V. Vishnevskogo. 2015;10(1):3390 . [In Russian].

5. Masayuki Ohta, Yukio Iwashita, Kazuhiro Yada. Operative Timing of Laparoscopic Cholecystectomy for Acute Cholecystitis in a Japanese Institute. 2012;1(16):65-70.

6. Lohvickij SV, Ceshkovskij MV. Simul'tannye operacii pri posleoperacionnyh gryzhah i kal'kuleznom holecistite. Annaly hirurgicheskoj gepatologii. 2007;3:83-4. [In Russian]. 